\title{
Efficiency of Computer Application on Administrative Affairs of Universities
}

\author{
Beixiong Gao
}

Xi'an Aeronautical Polytechnic Institute; Xian 710089 China.

\begin{abstract}
Keywords: Computer; Application; Administrative Affairs in Universities; Efficiency.
\end{abstract}
\begin{abstract}
With the rapid development of social economy in our country and the rising level of science and technology, computer technology is more widely applied playing a very important and irreplaceable role in various fields of society. The universities in our country shoulder the responsibilities of training and transporting talents. So it's necessary to adopt scientific management and apply modern computer network technology to enhance their competitiveness and better do the work of personnel training. Based on the specific application of computer network technology on administrative affairs, this paper analyzes the existing problems in the process of applying computer network technology and puts forward some suggestions for how to improve its efficiency. It's expected that the theoretical research can benefit for the development of administrative work in various universities.
\end{abstract}

\section{Introduction}

Nowadays, the role of administrative affairs management in universities is increasingly apparent. Being scientific or not sometimes even determines the development of universities. The universities all strengthen the management of various administrative affairs based on that, aiming at promoting the development of schools better and achieving to train a large number of talents for society. Meanwhile, computer network technology is applied effectively in more fields and plays a very important role for its being increasingly innovative and complete. This technology applied in the administrative affairs management of universities promotes the modernization and scientification of management and enhances the efficiency and quality of management. But what needs to pay attention is that there still exist lots of problems in its process. It causes to make no full use of the technology's function and value, and to make the management of administrative affairs not combined well with the demands of schools. This paper analyzes the application of computer network technology in the process of carrying out the administrative work, and puts forward some suggestions to expect to benefit the development of work based on better realizing the value of computer network technology and enhancing the efficiency of administrative affairs management.

\section{The Computer Management Ideas of Administrative Work in Universities}

In the past, the management and handling of administrative affairs mainly use paper documents as carriers and use files, filing cabinets for safekeeping. Gradually, for the contradictions between ever-increasing documents and a fixed area for storage being increasingly apparent, it demands new requirements for administrative affairs management in universities. The problem is solved effectively with computer network technology being completed and widely applied. The electronic document can carry more information and process more data, more importantly, it almost can not occupy too much space. The function of computer management mainly manifests in the following points:

\subsection{Strengthening Control of Various Affairs by Using Computer Network Technology}

The administrative staff in schools should deal with all kinds of affairs everyday. If computer network technology can be used and corresponding network system can be established, they will search for the information and documents they need and be access to the data of various departments at any time and any place. Generally speaking, applying computer network technology greatly improves 
the efficiency of administrative staff to ensure a normal development of other work in schools. Besides, establishing an integrated network system can strengthen the communication among various departments in schools, deliver the important decisions quickly, effectively contact with the outside world and improve the accessibility of information.

\subsection{Achieving to Integrate and Manage Archives Effectively by Using Computer Network Technology}

The establishment and management of archives in universities is one of important components of administrative management work. For a huge number of students in universities, carrying out the archival work is quite complicated. Applying the computer will greatly increase the efficiency of the work. For example, after computer networking, the directives and demands of the superior can be reached instantly to the computer of the subordinate. And there's no need to recognize the leaders' handwriting for being normal of computer writing. Besides, using computer to establish archives can achieve to make a catalogue and retrieval quickly, and its accuracy is far higher than the relevant staff. All in all, applying computer technology in establishing and managing the archives not only can effectively improve the work efficiency, but also improve the accuracy and normality of archives management work. It demands that the relevant staff can conform to the changing trend of the times, change their inherent thoughts and accept the application of this technology to take a historic step forward.

\subsection{Improving Work Efficiency of Personnel Management by Using Computer Network Technology}

The personnel management department is primarily responsible for integrating and safekeeping various materials of staff from entry to retirement. In the past, carrying out this work mainly depends on handwriting materials. So it may cause problems for carrying out other work for they being very easy to be lost and damaged over time. But if it's accessible to use magnetic materials, which means using computer technology, that will be more beneficial to integrate and report the data, rather than make lots of space available for storing paper materials and read files a lot to look for a personnel information. These all promote the work to carry out more effectively.

\subsection{Achieving the Scientific and Regularized Teaching and Administrative by Using Computer Network Technology}

The academic administration office is an important department of teaching management, its work being complicated. Firstly, to establish and manage student status information, then to plan and adjust the corresponding teaching plan according to specific conditions and to file salaries for teaching staff...but these will be not problems if a set of scientific management procedure is established by using computer. For example, managing student status information can use computer to establish a data base and store or assign out their information at any time and any place. The plan and adjustment of the teaching program can use computer to generate automatically to ensure the teaching work to go on. Filing the salaries of staff can use relevant financial software system to improve its efficiency and accuracy. And other series of situation questionnaire also can achieve the integration and analysis processing of data by computer to promote other works to develop.

\subsection{Achieving to Make Full Use of Functions of Various Departments by Using Computer Network Technology}

Various departments in universities have different functions. Being purposeful and selective to use the computer according to their own functions can effectively exert their functions. For example, for the department responsible for library management, it can use computer network technology to do an automatic retrieval of library information and make the relevant department know the library information in time, effectively supervising this aspect of affairs. Besides, networking through microcomputers among different universities, it can achieve a rational allocation and high-efficient utilization of library resources, and greatly reduce the funds of purchasing books for various universities. 
All in all, the computer widely applied in the administrative management work in universities plays a very important and irreplaceable role. It is one of the important material conditions for this work being scientific and regularized.

\section{The Advantages of Computer Management of the Administrative Work in Universities}

\subsection{Sufficient Professionals}

The administrative work just starts in our country, but the training of computer professionals begins to take shape. It can transport lots of specialized personnel for developing the work to improve the relevant administrative team.

\subsection{Tendency of Social Development}

With the change and development of the times, especially the gradual establishment of our socialist market economy, there are greater demands and better requirements for talents. It demands that the departments and the staff can change working style at the proper time, emancipate the traditional working thoughts, enhance the competitive awareness and be dare to meet the challenge, to train more useful talents for our society and our country.

\subsection{Importance Attached by Our Country to the Education}

It's generally known that talents are the important foundation of the development of our country. So the state pays high attention to the education career, coming out a series of policies conductive to it. These provide guarantees of system and policies for the application of computer management in administrative affairs in universities. Meanwhile, the state increases the investment in this aspect. It makes the application of computer management bring benefits to universities in more regions and more departments in their own university, achieving a remarkable improvement of the quality and quantity of administrative management in universities. All in all, the importance attached by our country directly promotes a extensive and high-efficient application for computer management.

\subsection{Strong Desire of Self Improvement}

The staff in various universities have realized that it's an inexorable trend of the development of education to improve the administrative management work. Therefore, expecting to use the computer network technology rationally enhances own competitiveness and educates more useful talents for the society.

\section{Application Difficulties of Computer Management in Administrative Work in Universities}

\subsection{Administrators Being Quite Complicated}

The staff who participate in this work cover various posts in schools and they all have certain specific work. So there come out many problems in the process of developing the work. What's more, some administrators are lack of mastery of new technology and have poor learning ability for them being quite older. It severely hinders the development of the work.

\subsection{Administrative Department and Its Staff Being Lack of a Sense of Crisis}

The administrative departments in some universities still exist a phenomenon "eating from a big pot", so the staff are prone to be lack of a sense of crisis. They think that reforming or not cannot affect their interests, so they have chosen to ignore their obligations, and that makes the work progress at a slow pace.

\subsection{Unbalanced Development of Universities}

The universities in different regions have different economic power. Some universities operate it with difficulty and they have no capital to carry out the work. Besides, there are also some universities lack of paying attention to the work, with no plan to devote certain manpower, material resources and financial capacity to it. Under this circumstance, to achieve computer management of administrative affairs is an empty talk. Therefore, the universities must increase capital investment and be equipped with special management personnel, which may be possible to implement this work. 


\section{Specific Measures For Strengthening Computer Management of Administrative Work}

\subsection{Heightening the Ideological Understanding of Relevant Staff}

For strengthening computer management of administrative work, it's firstly necessary to heighten the awareness of the staff for the work to make them realize the function and value of computer management for administrative affairs in universities, and promote them to participate in the work actively. Meanwhile, it's also necessary to guide the staff to overcome the fear of hardship, to innovate boldly and to constantly improve their professional quality, better serving for the development of the work.

\subsection{Increasing the Capital Investment}

All work cannot be carried out without the support of material conditions. For the application of computer, the relevant departments of universities should enhance the financial support to lay a solid foundation for carrying out the work. Also, the importance should be attached to the training of professional talents to make the administrative team grow steadily.

\subsection{Establishing and Improving the Relevant System}

The universities can list the computer management as a special provision to make the staff of administrative department consciously use modern methods of management in the actual work, effectively improving the work efficiency and laying a solid foundation for carrying out the work.

\subsection{Strengthening the Interaction and Communication Among Universities}

Different universities can meet different problems when carrying out the work, and also can sum up some experience. And the interaction and communication among universities makes them share those experience and finally achieves common development.

\section{Conclusion}

Generally speaking, achieving a wide application of computer management in the administrative work of universities cannot accomplish at one stroke. It needs to take a long process. While concretely implementing the work, the different subjects need to shoulder their own responsibility, actively participate in the work and coordinate mutually, jointly devote to a scientific and regularized development of administrative work in universities, to train more useful talents for our society and our country.

\section{References}

[1]. Luo yangyang. Design and realization of student affairs management system in universities based on mobile Internet [D]. Henan Normal University, 2015.

[2]. Shang yumei. Design and realization of reservation administration software of university office [D]. University of Electronic Science and Technology of China, 2014.

[3]. Liu gaosheng. Research on the efficiency of administrative work in universities [D]. Southwestern University of Finance and Economics, 2014.

[4]. Zhang wei. Design and realization of administrative work management system in universities. Jilin University, 2013.

[5]. Fang da. Design and realization of administrative work automatic system in universities [D]. Fudan University, 2011.

[6]. Zhao qing. Application of computer on administrative management in universities [J]. Qingdao Education Forum, 1998, (01):33-34+36.

[7]. Qin jian. Application of computer on affairs management in universities [J]. Learning Forum, 1995, (01):40-41. 